\title{
Assessment of the knowledge and attitude of nursing personnel on prevention and control of perinatal transmission of HIV/AIDS in selected Government hospitals in Himachal Pradesh
}

\author{
Krishna chauhan \\ Principal, Sister Nivedita Govt. Nursing College, I.G.M.C. Shimla (HP)
}

\begin{abstract}
:
Background: HIVIAIDS has emerged as a major health problem and challenges to health services. It has grown to a size of pandemic affecting over 17 million persons all over the world. In parts of north east India, widespread injecting drug use helped to spread HIV infection, whilst a different pattern was seen in southern and western states with prevalence levels of 25-71\% amongst sex workers in cities including New Delhi, Hyderabad, Vellore and Mumbai.

Objective: To Assess of the knowledge and attitude of nursing personnel on prevention and control of perinatal transmission of HIV/AIDS.

To find out the relationship between:- knowledge and attitude of nursing personnel

Design: Co relational research study

research Setting: Selected Government hospitals in Himachal Pradesh.

Participants/ Patients: The study was conducted in the two selected Government hospitals of Himachal Pradesh from 2009-2010. Purposive sampling technique was used for the selection of sample subjects. Total sample 100 nursing personnel were enrolled in the study.

Material and Methods: A structured knowledge questionnaire was prepared to assess the knowledge of nursing personnel. An extensive review of research literature related to perinatal transmission of HIV/AIDS. Peer group discussion was held. Opinion of experts were sought to ascertain the clarity and appropriateness of the items. A blue print was prepared for specifying the various domains of objectives and content area. Blue print indicates the relative weight-age given in terms of percentage of items for each content area. Structured questionnaire was prepared to determine the attitude of nursing personnel regarding perinatal infection of HIV/ AIDS. Attitude items concerning attitudes related to HIV/AIDS. Sixteen declarative statements were developed. Each statement with five alternative responses:- strongly agree, Agree, Neither agree, Nor disagree, Strongly disagree, Disagree and a remarks column. Positive statements were scored 5,4,3,2,1, and negative statements were scored 1,2,3,4,5, respectively. The time taken for completing the structured knowledge questionnaire varied from 40-45 minutes and for attitude questionnaire $7-10$ minutes. A pilot study was conducted to see the feasibility and practicability of study. To ensure the content validity of the tool, the questionnaire of knowledge, and attitude were submitted to experts. Comments and suggestions made in the final draft. Permission was taken from ethical committee.

Result: Majority of the nursing personnel belonged to the age group below 30 years (68\%).Most of them had higher secondary education (53\%).Majority of nursing personnel having diploma in nursing (98\%).Majority of the nursing personnel having 1 to 5 years of total experience (70\%).Majority of the nursing personnel having more 1 to 5 years working experience in maternity unit (69\%).Majority of the nursing personnel did not attended any in service education/workshop on HIV/AIDS prevention (59\%).Majority of the nursing personnel had workshop on HIV/AIDS and STD prevention (76\%).Majority of the nursing personnel had inservice education for 105 days (83\%).Mean score of knowledge was 23.Median score of Knowledge was 22.S.D. of knowledge was 6.Mean score of attitude was 55.Median score of attitude was 54.S.D of. attitude was 5.86.

Conclusion: Findings of the study revealed the majority of nursing personnel had inadequate knowledge regarding prevention and control of perinatal transmission of HIV/AIDS and also revealed positive attitude despite fear, apprehension, and interestingly showed willingness to work with HIV/AIDS client. There is need to plan and conduct accelerated HIV/AIDS training programme which will remove existing apprehension, fear, and prejudices towards HIV/AIDS. That may enhance knowledge; improve attitude and willingness to provide comprehensive, compassionate care for clients with HIV/AIDS.
\end{abstract}

Key words: HIV/AIDS, Perinatal transmission, Knowledge, Attitude, Nursing personnel

\section{Introduction:}

The HIV that causes AIDS was discovered by scientists in France in 1983. Alex Seumatoff reported that this virus was found in green monkeys on the continent of Africa; therefore, theory is that the infection 
crossed-over from monkeys to human. People in Africa live in close contact with green monkeys. People all over the world are merging and mixing together, since the last few decades, thus the virus is moving from continent to continent. According to Dr. Alton Stone, This virus is very cleaver, it changes all the time.

WHO (1992), two types of HIV have been firmly defined; HIV-1 which is pandemic and HIV-2 which is more geographically restricted in distribution. That HIV enters the body system through unprotected sex with an infected person; through contaminated blood and blood products (blood transfusion); infected medical instruments or skin piercing equipment and through an infected mother

Adler (2001), a causative organism, lymphadenopathy virus (LAV), was discovered by Barre-Sinoussi and colleagues (1983). T cell lymphotrophic virus type- 3 (HTLV III) was described by a team led by Gallo in 1984. Human Immuno deficiency virus (HIV-1) became the agreed term later in 1984 for this retrovirus. HIV is divided into three groups: M, N and O. Group O, identified in the Cameroon in 1984, is extremely rare. In group $\mathrm{M}$ there are at least nine sub-types of HIV -1, alphabetically designated, that have so far been described.

UNICEF (2004), the number of AIDS orphans Worldwide could reach 25 million by 2010, 40 million by 2020 . The situation is quite dramatic. If we don't achieve a lot rapidly, the epidemic will be comparable in five to ten years to the situation in Sub-Saharan Africa

NACO, (2008), in India, more than 1, 88,000 people living with HIV/AIDS were accessing ART from public sector hospitals/clinics as on November 2008.

Frohlich, Abdool Karim, \& Abdool Darim (2007) a comparison to India, in rural Sub. Saharan African countries the prevalence of both HIV and sexually transmitted infection continue to be high.

Singh (2002) A study conducted in Delhi to assess knowledge, attitude, perceived risks of infection and sources of information about HIV/AIDS among 911 pregnant women belonged mainly to middle or lower socioeconomic status and large proportion were illiterate. The female literacy in India and Delhi was 55\% and 75\% respectively. National Annual Sentinel surveillance among pregnant women reported $0.25 \%$ prevalence of HIV infection in the year 2000 .

\section{Methods}

A descriptive-correlation survey design was used to conduct the study to the assess the knowledge and attitude of nursing personnel on prevention and control of perinatal transmission of HIV/AIDS and to seek the relationship with selected factors in selected Government hospitals in Himachal Pradesh. The conceptual model for the study was based on the cognitive theory of motivation, theory of attitude formation, theory of reasoned action, theory of inter-personal relationship and concept of anxiety in devolving the frame work of the study.

The study was conducted in the two selected Government hospitals of Himachal Pradesh from 2009 2010. Purposive sampling technique was used for the selection of sample subjects. Total sample comprised of 100 nursing personnel.

Data gathered were analyzed and interpreted in the light of the objectives by using the descriptive and inferential statistics in terms of frequency percentage, mean, standard deviation, chi square value and coefficient of correlation.

\section{Criteria for selecting the sample}

The sample subject includes the nursing personnel who fulfilled the following criteria

1. Nursing personnel having working experience of more than 1 year

2. Nursing personnel who were available during data collection

3. Nursing personnel who were willing to participate in the study

4. Nursing personnel who can read and understand English

Based on conceptual framework and objective of the study, the following tools were developed in order to obtain required information:

1. Structured knowledge questionnaire was prepared to assess the knowledge of nursing personnel on prevention and control of perinatal transmission of HIV/ AIDS

2. Structured attitude questionnaire was prepared to assess the attitude of nursing personnel regarding prevention and control of perinatal transmission of HIV /AIDS

Paper pencil technique were used for assessment of knowledge and attitude by self- administered questionnaire Formal administrative approval was obtained for conducting pilot study in the month of October (5-102009 to 15-10-2009) in Safdarjung hospital and Lok Nayak hospital, New Delhi. 40 (forty) nursing personnel were selected by purposive sampling technique.

The pilot study is designed to find out the feasibility of conducting the study checking the reliability of the tools and to decide the plan of statistical analysis 
Nursing personnel were selected by using purposive sampling technique. Self introduction and introduction to the nature of the study were given to nursing personnel to obtain free and frank response. The purpose of the study was explained to the samples and confidentiality of their response was assured.

The time taken for completing the questionnaire ranged from 50-55 minutes. The researcher was satisfied with feasibility of the tool.

Findings revealed that it was feasible and practicable to conduct the study and criterion measure was found to be effective. Therefore, the plan for data collection was finalized and remained the same as for the pilot study with some modification of the tools. No major problems faced while conducting the pilot study.

The reliability of tool was established by KR -20 formula \& Crohn Bach's alpha

- Reliability of knowledge questionnaire (KR-20) $\quad 0 \quad 0.918$

- Reliability of attitude (Crohn Bach's alpha) $\quad=\quad 0.779$

Formal administrative permission was obtained from the administration of Kamla Nehru Hospital Shimla, and Deen Dayal Hospital Shimla, Himachal Pradesh. The final study was conducted from the $25^{\text {th }}$ December 2009 to $15^{\text {th }}$ January 2010, according to the research design. Data collection procedure remained the same as pilot study. Self-introduction and introduction to the nature of the study was given to the nursing personnel to free and frank response. The purpose of the study was explained to the sample and confidentiality of their response was assured.

For Descriptive statistics: - mean, standard deviation, frequency, percentages and for Inferential statistics:coefficient of co-relation and chi square test was calculated. CI of $95 \%$, p $<0.001$ was considered as highly significant and $\mathrm{p}<0.05$ as significant.

\section{FINAL DATA COLLECTION PROCEDURE}

Formal administrative permission was obtained from the administration of Kamla Nehru Hospital Shimla, and Deen Dayal Hospital Shimla, Himachal Pradesh. The final study was conducted from the $25^{\text {th }}$ December 2009 to $15^{\text {th }}$ January 2010, according to the research design. Data collection procedure remained the same as pilot study. The purpose of the study was explained to the sample and confidentiality of their response was assured

Result

Major findings of the study revealed that:-

Findings related to the sample characteristics of the nursing personnel:

- Majority $(\mathbf{6 8 \%})$ of the nursing personnel belonged to the age group below 30 years. Most $\mathbf{( 5 3 \% )}$ of them had higher secondary education. Majority $\mathbf{( 9 8 \% )}$ ) of nursing personnel having diploma in nursing. Majority $\mathbf{( 7 0 \% )}$ of the nursing personnel having 1 to 5 years of total experience. Most $(\mathbf{6 9 \%})$ of the nursing personnel having more 1 to 5 years working experience in maternity unit Majority (59\%) of the nursing personnel did not attended any in service education/workshop on HIV/AIDS prevention . Majority (76\%) of the nursing personnel had workshop on HIV/AIDS and STD prevention. Majority (83\%) of the nursing personnel had in-service education for 1 to 5 days

Findings related to the knowledge and attitude of nursing personnel regarding the prevention and control of perinatal transmission of HIV/AIDS

TABLE-1

Mean, Mode, Median, Standard Deviation, of Knowledge score of nursing personnel regarding prevention \& control of perinatal transmission of HIV /AIDS in total content area

\begin{tabular}{|l|l|l|l|l|l|l|}
\hline Area & $\begin{array}{l}\text { Maximum possible } \\
\text { score }\end{array}$ & Mean & Mode & Median & $\begin{array}{l}\text { Range of } \\
\text { score }\end{array}$ & $\begin{array}{l}\text { Standard } \\
\text { deviation }\end{array}$ \\
\hline Knowledge & 50 & 23.15 & 20 & 22 & $9-41$ & 6 \\
\hline
\end{tabular}

TABLE-2

Mean, Mode, Median, and Standard Deviation, of attitude scores of nursing personnel regarding prevention and control of perinatal transmission of HIV /AIDS in total content area

\begin{tabular}{|l|l|l|l|l|l|l|}
\hline Area & $\begin{array}{l}\text { Range } \\
\text { possible score }\end{array}$ & Mean & Mode & Median & $\begin{array}{l}\text { Range } \\
\text { obtained } \\
\text { score }\end{array}$ & Standard deviation \\
\hline Attitude & $16-80$ & 54.93 & 54 & 54 & $42-72$ & 5.86 \\
\hline
\end{tabular}


TABLE-3

Coefficient of correlation between knowledge and attitude scores of nursing personnel

$\mathrm{N}=100$

\begin{tabular}{|l|l|l|l|l|}
\hline Mean, mode, median \& Standard deviation & \multicolumn{3}{|l|}{} \\
\hline Variables & Median & Mean & Standard deviation & "value \\
\hline $\begin{array}{l}\text { Knowledge scores } \\
\text { Attitude scores }\end{array}$ & 22 & 23 & 6 & \multirow{2}{*}{0.164} \\
\cline { 2 - 5 } & 54 & 54.93 & 5.86 & \\
\hline
\end{tabular}

df $(98)=0.195$ at 0.05 level

Findings related to association of knowledge scores of nursing personnel with the selected factors.

- There is significant association of knowledge scores of nursing personnel with the professional working experience (total), working experience in maternity units, \& specified areas of workshop.

- Chi squire value of professional working experience (total), working experience in maternity units, and specified areas of workshop mean score were (7.472), mean score were (8.507) and mean score were (6.745) respectively on the level of significant for a degree of freedom of 0.05 level.

\section{Discussion}

In the present study, Findings revealed the majority of nursing personnel had inadequate knowledge regarding prevention and control of perinatal transmission of HIV/AIDS. Findings of the present study were consistent with the findings of these studies Allekutty, (1991), Asha Qureshi (1992), Kamlesh Bajaj (1993), Munimmal (1994), Usha Denial (1995), Senthil kavita et.al. (2008), Anne.B. wiliam (2006) Reader I ( 2001) all reported lack of information/ knowledge among nurses about HIV/AIDS

Findings highlights in this study that nursing personnel have some awareness in certain areas of HIV/AIDS but by and large they lack information on certain important areas of perinatal transmission, prevention \& control of HIV/AIDS, clinical manifestation, Antiretroviral Therapy to HIV positive mother and HIV positive neonates. These findings were somewhat similar with the findings with Asha Qureshi (1992), Kamlesh Bajaj (1993), Walsuimbi, Mariam et.al. (2004) revealed gap in knowledge in agents, roots of transmission, immunology of HIV/AIDS

Findings indicated significant association between knowledge score with working experience, maternity experience, and in service education variables these findings supported by Asha Qureshi (1992), revealed that ongoing

In-service education was the source of gaining more knowledge about HIV/AIDS in nurses working in referral hospital. These findings were consistent with Jell, Bormann (1999) Asha Qureshi (1992), Walsuimbi, Marium,et al.(2004) revealed fear of contagion to HIV/AIDS.The findings present study revealed positive attitude despite fear, apprehension, and interestingly showed willingness to work with HIV/AIDS client. Thus findings of the study suggested that, need to plan and conduct accelerated HIV/AIDS training programme which will remove existing apprehension, fear, and prejudices towards HIV/AIDS. That may enhance knowledge; improve attitude and willingness to provide comprehensive, compassionate care for clients with HIV/AIDS. This finding of the study was supported by Anne.B. wiliam (2006), Senthil kavita et.al. (2008), Peter, Delobellet.(2009), Asha Qureshi (1992), Allekutty, (1991). All these Studies emphasized for in-service education, workshop and training programmes on HIV/AIDS

\section{Implications of the study}

Current study result has following implications:

Implications for Nursing Education:

1. In-service and continuing education on HIV/AIDS infection, prevention and control should be systematically planned and conducted for all nursing personnel

2. Integration of HIV/ AIDS education will require teacher's preparation when the subject is introduced in actual teaching with schools / colleges

3. A well established continuing education department in the hospital must run these courses on continuous basis. The nurses must be sent out to attend conferences, workshops, symposiums, and seminars in their own country

\section{Nursing Administration:}

1. Administrator should take the initiative in organizing in-service education programme for nurse educator which enables them to update their knowledge and skill.

2. Administrator should change the attitude of staff towards clients and their family members with HIV infection. 
3. Administrator should encourage staff to participate in National HIV/AIDS programmes organized by any national agency

\section{Nursing Service:}

1. All the nursing personnel must be given in-service education on HIV/AIDS especially prevention of perinatal transmission of HIV/AIDS

2. A model ward with labour room facility to be set up for managing HIV/AIDS patient with provision of adequate supply of gowns, slippers, disposable syringes, to minimize the risk of infection and for training the nurses. This requires well qualified staff in the unit

\section{Nursing Research}

1. Research has a vital and significant role in nursing. Nurses recognize the need to develop body of knowledge to test the strategy to bring the new findings, current education in the field of treatment and quality care, so nursing research is essential

2. Nurse researcher should assess the effectiveness of various teaching strategies, prevention services and attitude of nursing personnel and other staffs towards prevention of HIV/AIDS to bring more effective changes

\section{Limitation}

- The study was confined to small number of nursing personnel (100) which limits the generalization of findings to only the study sample

- Generalization was limited to the two selected hospitals of Himachal Pradesh

- The study was limited to the hospital settings only.

- The study was limited to the one category of nursing personnel that is staff nurse only.

\section{Acknowledgement}

The present research project has been under taken and accomplished under the expert guidance and supervision of Dr. Molly Babu, Senior Lecturer, R.A.K. College of Nursing and Dr. R.G. Mathur, Ex Senior Lecturer, R.A.K. College of Nursing, New Delhi, Ms. Kalpana Mandal, Principal, R.A.K. College of Nursing, New Delhi ,Dr. Mrs. H. Goyal, M.N. Co-coordinator and all the faculty of Master of Nursing, R.A.K. College of Nursing, for their encouragement, suggestions .

My heartiest thanks to my loving husband Mr. Prem Jhagta, son Risabh, and my parents for their patience, constant moral support and encouragement throughout the study to complete it in the best possible manner Above all I bow my head before God Almighty and express my heartiest gratitude to Him for his abiding grace and being the guiding force behind my work.

Conflict of interest: There is no conflict of interest.

Funding source: self financed.

\section{BOOKS}

\section{References:}

[1]. Abdellah, F.G. and Eugene, L. "Better patient care thorough nursing research" $2^{\text {nd }}$ edition, New York: Macmillan, 1979.

[2]. Adler M.W. “ABC of AIDS", $5^{\text {th }}$ edition. BMJ Books, London, 2001.

[3]. Andreasson et al. "Prevelence of HIV virus in antenatal mother" Year 1993.

[4]. Association of British Insurers, "ABI statement of practice:

[5]. underwriting life insurance for HIV/AIDS". ABI, London, 1994.

[6]. B.T. Basavanthappa, Nursing Research, $1^{\text {st }}$ edition, New Delhi, Jaypee Brothers, year 2007.

[7]. Compbell W.G. and Stephen, B.V. Form and style in thesis writing. Boston; Houghton mifflin company, 1972.

[8]. for development of national AIDS prevention and control programme by WHO, $1^{\text {st }}$ ed. New Delhi, B.R Publisher, 1991.

[9]. Polit and Hungler. Nursing Research: Principles and Methods. $6^{\text {th }}$ edition lippin cott co. 1999.

[10]. Sherr L. "HIV/AIDS in mothers and babies: a guide to counselling". Blackwell Scientific, London, 1991.

[11]. WHO series 3 "Guideline for nursing management of people infected with HIV virus" New Delhi Reasonable office for South East Delhi 1998

[12]. WHO case definition of HIV surveillance and revised clinical staging and immunological classification of HIV related disease in Adults and Children. 2006

[13]. WHO. "New data on the prevention of a mother to child transmission of HIV and their policy implication", Geneva; WHO, 2001, pp 11- 13 .

\section{JOURNALS}

[14]. Andreasson P.A. Dias F, Naucler A et al. "A prospective study of vertical transmission of HIV-2 in Bissau, Guinea-Bissau". $\underline{\text { AIDS, }}$ 7: $989-993$.

[15]. Anderson, D.G. et al. "Knowledge, attitude, beliefs \& behaviours different in rural nurses". Journal of advanced nursing, 1990, June, 52(6), 620-630.

[16]. David N. Burns, et al. "Cigarette smoking, premature rupture of membranes, and vertical transmission of HIV-1 among women with low CD4+ levels". AIDS, 1994, 7:718-726 
[17]. Senthil Kavita, et al. "Nursing care for Patients with HIV/AIDS". Nursing journal of India, 2008, Jan. 3:53-54.

[18]. Sherr L. Hedge B. "The impact and use of written leaflects as a counselling alternative in mass antenatal HIV screening". AIDS Care 2(3): 235-245.

[19]. WHO, "guidelines for nursing management of people infected with HIV". The nursing journal of India, LXXX:2:44-47, 1989.

[20]. WHO-UNAIDS HIV vaccine initiative. "Available at www.who.int/HIV vaccines. Accessed 30 May 2002

[21]. World Health Organization "Preventing mother to child HIV transmission". Press Release WHO/70 from the WHO technical consultation. October 2000, www.who.int/inf-pr.2000/en/pr2000.70html

\section{WEBSITE}

1. WWW.http\#nacoonline.org

2. www.http\#aidsinfo.nih.gov

3. www.http\#cwac.org

4. www.http\#worldaidsday.org

5. www.http\#unaids.org 